\title{
A experimentação política
}

L'expérimentation politique

\author{
Olivier Neveux
}

Olivier Neveux

Professor de história e estética do teatro na École Normale Supérieure (ENS) de Lyon. Editor da revista Théâtre/Public.

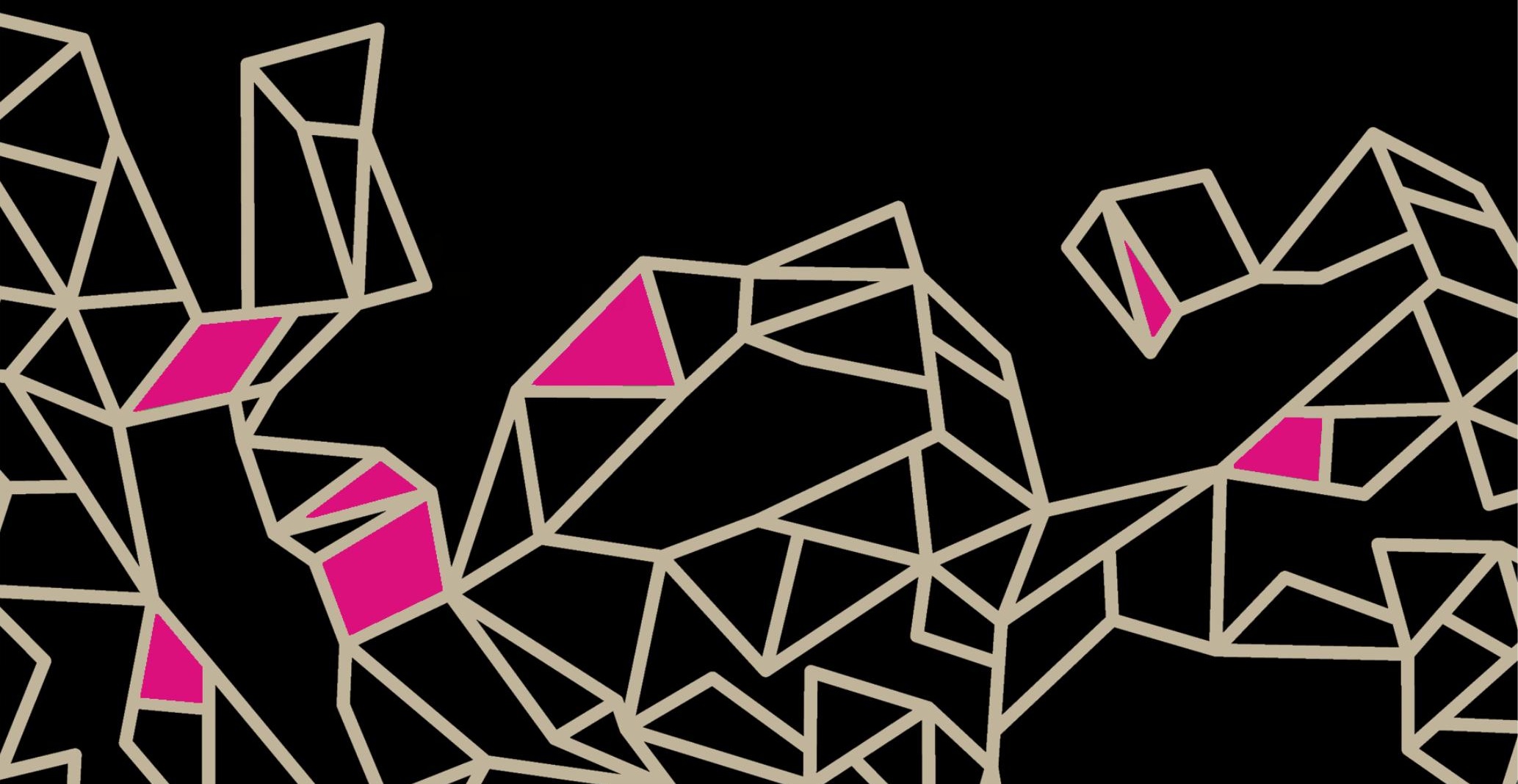


Publicado In: NEVEUX, O. L'experimentation politique. In: LoscoLéna, M. (dir.). Faire théâtre sous le signe de la recherche Rennes: Presses Universitaires de Rennes, 2017. p. 293-303.

Depois de Jacques Rancière, a palavra "política", ao que parece, deve ser pensada como objeto de um "mal-entendido" (RANCIÉRE, 1995). A própria polissemia da palavra permite que ela se refira, simultaneamente, e entre outras coisas, ao zelo dos "detentores de poder" do Capital e às "vagarosas impaciências" militantes; às terríveis violências estatais e às construções utópicas muito localizadas; ao horror do comunismo realmente existente e também a seu poder heróico. Não há lugar para lamentações. A "política", feita de interesses contraditórios, significa tudo isso ao mesmo tempo. E a abordagem taxonômica, infelizmente tão difundida, ao tentar enquadrá-la numa definição fixa, nada ensina sobre as lutas de significação e orientação que a definem e redefinem, de acordo com as conjunturas.

Neste trabalho, a política será designada como aquilo cuja orientação se inscreve, com mais ou menos radicalidade, numa constelação heterogênea de posições anticapitalistas, ou críticas do capitalismo - de esquerda. Quando a política não se reduz à expressão de opiniões, ela consiste, praticamente, em dois aspectos que se implementam de forma variável: intervenção e transmissão. A intervenção designa a inscrição nas coordenadas do tempo presente de um ato - que pode ser verbal, simbólico, eleitoral, de combate; e a transmissão caracteriza a necessidade de que se organize a inteligibilidade desse ato. A forma tomada pela prática política de hoje oscila, de modo massivo, entre esses dois polos: ações e pedagogias. É importante ressaltar que a ação e a transmissão são também fatores de experiência, e mesmo de aprendizado: viver uma luta, construir uma mobilização, se inscrever num movimento, isso nunca será uma aventura anódina. A exceção que isso supõe, diante dos tempos correntes, a transformação (substancial) de pensamentos e atitudes quando se fazem coletivos, a redistribuição de emergências, da norma e dos hábitos, os rituais e suas transgressões, as alegrias singulares: são elementos que a razão evidente ignora ou subestima. Assim como o trágico que pode se desdobrar ali, mesmo em miniatura. Mas a experiência própria que a política oferece se encontra também no cotidiano - fora do evento - nas reuniões, pesquisas, verificações, 
numa certa disponibilidade para o presente e no trabalho do seu pensamento: nos abalos, na aparição de novas questões, na constituição das palavras de ordem ou de desordem etc. ${ }^{1}$

Uma terceira dimensão da política é muitas vezes ocultada e diminuída. No entanto, ela se revela como uma de suas partes determinantes: a criação. Considerar a política como uma criação é condição decisiva para afastá-la do modo circular e repetitivo com que tem sido adotada, para romper com seu futuro previsto, o já escrito, com reflexos ou receitas, indiferentes à situação concreta. Devemos concordar: a política nunca é exclusivamente "nova". Corre o risco do oportunismo a prática política que está constantemente sujeita a mudança circunstanciais, obcecada pela novidade. Ela exige, assim, duração, repetição, fixação, perseverança - há conquistas, heranças (mesmo que venham "sem instruções de uso") (BENSAÏD, 2001, 2002).

Esquematicamente, é possível distinguir três tipos de criação - sem que umas ou outras sejam, de fato, exclusivas. Dizemos que a política cria uma situação quando ela modifica uma relação de forças, quando contribui com a luta pela hegemonia, quando participa do surgimento de uma existência ou de um discurso antes invisível ou desorganizado, quando instrui os tempos ou a efetividade da transição. Dizemos que a política cria uma disposição quando ela modifica os laços que mantém com a economia, com o social, com a estética, quando redesenha os contornos de sua definição ou de sua "aplicação", quando inventa novas modalidades do seu próprio exercício. Por fim, diz-se que a política cria uma experimentação quando modifica as relações sociais hic et nunc, quando interrompe sua suposta naturalidade, quando inventa a experiência de sua emancipação.

Entender a política como experimentação é sustentar que ela é conduzida por hipóteses, por sua aplicação - retificada pela realidade. Essa dimensão é frágil, sempre suscetível de redundar numa formulação arrogante, obcecada com seu próprio projeto e desdenhosa do real - e "o real só é real porque nos desmente" (THÉVENIN, 1991, p. 69). Construção que corre o risco de imitar uma "Ciência", neste caso, fetichizada: é importante não subestimar

1 Ver, pelo contrário, as críticas destinadas à militância: OJTR (Organisation des jeunes travailleurs révolutionnaires) (ORGANISATION DES JEUNES TRAVAILLEURS RÉVOLUTIONNAIRES, 1992; LE JARDIN S'EMBRASE, 2007). 
o impasse científico no qual uma parte do movimento operário se confinou, a glaciação produzida por uma certa "corrente fria" de muitos impulsos e tentativas. Positivista e mecanicista, a construção de uma Ciência da História ou de uma Ciência como um puro baluarte à ideologia certamente contribuiu, sob o pretexto de uma produção teórica e política nova, para abstrair a política da prática, e de suas dimensões seculares.

\section{Brecht e a experimentação}

Mas o que dizer, diante dessas observações sobre "teatro político" se entendemos por isso um teatro que pratica política?

O exemplo de Brecht é, certamente, impressionante pois ele articula a seu projeto, sua teorização e uma metodologia bem fundamentadas. Um texto, publicado em 1948 pela "Associação Suíça de Estudantes Socialistas", mas proveniente de uma palestra dada em 1939 em Helsinque, intitulada "Sobre o teatro experimental" permite identificar sua dinâmica. Ele é constituído de uma análise global (perspectiva histórica, pontos constitutivos da situação) e de uma dimensão programática.

Este texto se organiza em torno da atualização de uma contradição: à partir das propostas "naturalistas" e "expressionistas" - Brecht enfatiza as determinações sociais que as permitem e explicam - "os dois elementos constitutivos do drama e do teatro, a diversão e o ensino, entraram num conflito cada vez mais agudo" (BRECHT, 2000, p. 318), que assim distingue a conjuntura da "estética burguesa revolucionária" (Diderot, Lessing) onde essas duas funções foram articuladas. Brecht reconhece o alcance, a variedade $e$ a importância das pesquisas vinculadas à "diversão": "elas enriqueceram espantosamente os meios de expressão do teatro e, sem dúvida, aumentaram sua capacidade de divertir" (BRECHT, 2000, p. 312). O balanço é claramente menos favorável em relação ao elemento didático. A descrição que Brecht faz dele é severa. A conclusão do balanço sustenta a distinção confirmada entre os dois: "o aumento da capacidade de diversão do teatro acompanhou o desenvolvimento da técnica ilusionista; o aumento do valor didático foi acompanhado pela decadência do gosto artístico" (BRECHT, 2000, p. 315). A clivagem produz - tanto quanto é produzida por - esse frenesi experimental: 
"desenvolvemos um aparato técnico e um estilo de jogo mais aptos a gerar ilusões do que a comunicar experiências, mais a gerar embriaguez do que a convocar à revolta, portanto, mais apto a enganar do que a esclarecer" (BRECHT, 2000, p. 319-320). Brecht observa: "A evolução pressionava por uma fusão das duas funções do teatro, a fusão da diversão e da aprendizagem" (BRECHT, 2000, p. 320). O resultado para ele reside, como sabemos, na tomada de consciência pelo teatro de sua nova função social. O método de análise de Brecht utiliza as ferramentas do materialismo histórico - e do "grande método." Ela lhe deduz a obsolescência de certas formas, estabelece os elos da heteronomia que ligam a arte ao macrocosmo social e histórico. Ela coloca hipóteses ("o prazer artístico ainda é possível sem identificação, ou, pelo menos, em outra base que não seja a identificação? O que poderia fornecer tal base? (BRECHT, 2000, p. 325)).

Brecht descreve o trabalho em andamento:

\begin{abstract}
A técnica do distanciamento foi desenvolvida na Alemanha ao longo de uma nova série de experiências. No teatro Schiffbauerdamm, em Berlim, tentamos desenvolver um novo estilo de jogo com a colaboração dos atores mais talentosos da geração jovem [...]. Então esse novo estilo de jogo é o novo estilo, é uma técnica finalizada que pode ser claramente definida, o resultado de todos as experiências? Resposta: Não. É um caminho, aquele em que embarcamos. Os testes devem continuar. (BRECHT, 2000, p. 329)
\end{abstract}

Várias observações emergem deste rápido resumo da conferência de Brecht. A primeiro, a mais óbvia - mas que mesmo assim deve ser lembrada na medida em que a historiografia teatral, muitas vezes, deixa de mencioná-la, reservando ao "teatro de arte" o monopólio da pesquisa - "o teatro político" também é um local de experimentação, de pesquisa - embora seja notável que a categoria "vanguarda" geralmente o inspire menos do que a de "popular". Listar alguns nomes de destaque na história do "teatro político" no século XX (e mesmo permanecendo, injustamente, num um único "Panteão": Piscator, Brecht, o Living Theatre, Adamov, Gatti etc.) nos permite, num olhar, ver o alcance das invenções e tentativa praticadas. Obviamente não há razão para ignorar suas repetições, sua preguiça, suas caricaturas, para reescrever essa história apenas em termos de criação, em suma, para unificá-la artificialmente. O teatro político 
é um todo vasto e contraditório que inclui, em grande parte, o que não se pode negar, a preocupação experimental. Mas nesses casos, a pesquisa sempre se conduziu com uma viva desconfiança do formalismo ou, mais precisamente, em relação ao que era percebido como uma indiferença sobre o todo social.

Qual a utilidade de uma cena construtivista se ela não for socialmente construtiva? De que servem as mais belas instalações elétricas se elas apenas iluminarem representações falsas e infantis do mundo? Qual o sentido de toda uma arte de jogo baseada em sugestões se ela apenas servir para nos fazer tomar $X$ por $Y$ ? De que serve toda essa caixa de ilusões se ela estiver a oferecer apenas substitutos de aventuras reais? Esse destaque perpétuo de problemas que ainda permanecem sem solução? Esse aborrecimento não só dos nervos, mas da compreensão? Não podíamos ficar aí. (BRECHT, 2000, p. 320)

Mesmo que todo o teatro político não se organizasse em torno da categoria de utilidade, tão valorizada por ele, a hostilidade a uma pesquisa apartada do mundo é recorrente.

Sua pesquisa é estruturada com método. Sua forma é política. Ela ganha corpo numa análise da conjuntura político-estética e se orienta para um objetivo estratégico geral - que inclui a função renovada, revolucionada, do teatro. Ela se constrói num jogo de suposições e verificações, de conquistas e princípios. É praticada na tensão própria à intervenção política, capturada entre o estado real da situação concreta, a multiplicidade de fatores em ação, as urgências induzidas pela situação e a perspectiva geral com suas variações regionais, suas singularidades temporais, suas longas visões, suas apostas e hipóteses. Alimenta-se, em parte, de contribuições teóricas heterogêneas ao teatro - aqui, o marxismo, a dialética. De certa forma, o mundo e a história provocam a prática do teatro, mas sua transformação não pode ser mecanicista. A experimentação, assim determinada por seu exterior (na causalidade, na finalidade) é realizada na singularidade do objeto que investe. A política é a fonte de um andamento experimental.

\section{Políticas do espectador}

E se invertermos o olhar? É possível, de fato, modificar o hábito legítimo que consiste em identificar a presença (valor, efeitos, formas) da política 
na arte, a fim de questionar a relevância da arte para a política? O que, de fato, o teatro traz para a política ${ }^{2}$ ? Tal questão pressupõe a heterogeneidade de ambos: a política tem seus ritmos e atos, suas gramáticas e sua história; a arte, igualmente. A arte política não é um substituto à organização política, não é um partido (GARO, 2013). A homologia está rapidamente fadada ao fracasso quando não se percebem as especificidades de ambos - ela só funciona, imperfeitamente, para uma parte muito limitada do teatro político: as obras militantes.

A resposta brechtiana, por mais robusta, inaugural e revolucionária que seja, constrói o uso político do teatro em torno da dimensão didática: o teatro é um local ou meio de um conhecimento renovado, científico, das relações sociais - e por meio dele pode se iniciar, idealmente, uma controlada abordagem coletiva dessas relações. A experimentação é indexada a esta missão. Podemos imaginar a subtração do teatro (ou pelo menos sua desvalorização) dessa "visão pedagógica do mundo" (RANCIĖRE, 2009a) e sua inclusão em outras tentativas de criação política? O desafio não é propor um catálogo parcial ou exaustivo de obras criativas, nem de avaliar as propostas, mas aprofundar uma hipótese proposta em outro lugar (NEVEUX, 2013c).

O exemplo de Brecht pode introduzi-la. Bernard Dort observa, sinteticamente: "O principal em Brecht é [...] menos o distanciamento - ele continua sendo uma técnica e, de forma alguma, reflete uma situação ontológica (o distanciamento como resposta à alienação) - sendo antes a organização de uma nova ordem de relações, de uma nova dialética entre o palco, a sala e a história" (DORT, 1967). A proposta brechtiana embasa, de fato, a necessidade de uma transformação de relações que, majoritariamente, organizam a recepção da obra teatral. Além disso, ela pode ser entendida como um vasto e sistemático empreendimento teórico de refundações ou revoluções das múltiplas relações que organizam a atividade teatral. Uma relação, entre outras, é principal: aquela que liga a obra ao espectador e que, insiste Brecht, deve ser "transformada". Seu teatro é, de certa forma, a experiência concreta, tateante e revista dessa transformação. A leitura atenta do corpus teórico brechtiano revela, a este respeito, implicitamente, a existência de um "ideal do espectador". O comentário engraçado de Brecht sobre Marx no final dos anos 1920 não é insignificante ("o único

2 Há uma tensão semelhante no coração do teatro de agit-prop (IVERNEL, 1977). 
espectador que eu nunca imaginei" (BRECHT, 2000, p. 136)). Ele inicia um movimento irresistível: o estabelecimento de um espectador "teórico", presença ajustada à função reinventada do teatro - além disso, escreve Brecht: agora, "o espectador deve ser convidado a fazer um desvio (incomodado) e aprender algo antes de se estabelecer em sua cadeira" (BRECHT, 2000, p. 398).

De maneira mais geral: o teatro (aqui, o da "era da encenação") é, ao mesmo tempo, uma forma de expressão artística e prática social. Ele cristaliza um certo número de relações: o lugar que a obra ocupa no campo social, ou em relação às instituições, ou outras obras etc. Mas também, e o ponto é importante, o que pretende instituir em relação ao seu espectador. $O$ espetáculo constrói, com efeito, a partir dos requisitos intrínsecos de seu projeto, um lugar ou função ideal para o espectador (Brecht ainda, por exemplo, diz: "Portanto, acontecem menos coisas 'nele' do que 'com ele'” (BRECHT, 2000, p. 408-409)). Este lugar determina ou materializa a existência de uma relação, muitas vezes latente, prevista ou necessária. Seria preciso dizer ainda que a relação produz um lugar (mas a descoberta da relação é geralmente condicionada ao estudo do lugar). Essa relação teatral não é, em escala reduzida, a reprodução exata das relações sociais que organizam a sociedade: a obra é teatral, portanto, faz parte de uma história, com suas estruturas, suas próprias questões, suas diferenças. A política em jogo deve ser lida à luz dessa singularidade. Esta relação, então, traz um significado político - que deve ser interpretado e cuja interpretação é o possível lugar de um desacordo. Dito de outra forma: a obra produz uma política do espectador que, por sua vez, a determina. Esta não deve ser entendida como a política conduzida pelos espectadores, mas como a política que produz o espectador. Neste caso, esse espectador é, de certa forma, um espectador sem sujeito: essa função é vazia, abstrata - trata-se, aqui, do espectador, pois este é a unidade mínima necessária à criação de uma relação, no entanto, muitas são as obras que implantam uma política dos espectadores ou do público; este ponto é, além disso, um dos componentes da análise política. A interpretação política dessa relação "ideal" é aumentada, não mais diretamente legível, nem necessariamente mais consciente, mas menos discreta no contexto do "teatro político." Estudar o teatro político consistiria, assim, entre outras entradas, em questionar a forma dessa relação ou deduzi-la do local proposto, construindo-a politicamente. 


\section{Ensaios políticos}

É possível então, tal seria a hipótese conclusiva, considerar a obra teatral como politicamente experimental, entre outras coisas, em sua maneira de criar relações contraditórias, antecipadas e novas às relações sociais dominantes. Nesse sentido, é preciso distinguir duas dimensões: a da obra e do espectador, mas também a da obra, como mediação, entre o espectador e o mundo. Dois registros de perguntas trabalhadas diretamente por experimentações possíveis aparecem.

O primeiro diz respeito aos tipos de relações que o teatro pretende produzir, inventar, propor. Em um texto de 1968, retomado em 1971, Vitez escreveu:

Fazer teatro hoje é responder à pergunta feita há não muito tempo na França (vinte anos) pela primeira vez claramente por Jean Vilar: que forma encontrar expressando a nova relação que buscamos com o público? Pois não se trata apenas de pensar que devemos fazer uma nova arte para um novo público (afinal, por quê? por que esta equivalência automática?); não, eu estou falando sim de uma nova relação a ser inventada com o público. (VITEZ, 1998, p. 61)

Nesse sentido, o teatro pode fazer da questão da relação a se construir um dos desafios conscientes da experimentação - distinguir-se de outras relações em jogo, constituir-se sobre conquistas, retificar. Georges Bataille argumentou: "Um homem que escreve (no sentido de escritor) é um homem que não quer ser a coisa que o homem é para o empregador, e o mesmo ocorre com aquele que o lê" (BATAILLE, 1948, 1988). Em um mundo dominado e determinado por relações de sujeição salarial, que outros tipos de relações o teatro propõe - ou como trabalha o modo social atual, em sua redundância ou seu excesso? Parece possível acompanhar essa entrada e, assim, tentar identificar as formas que o teatro teria, na conjuntura, de não reproduzir um tipo de relação (evitar a reprodução das relações sociais num tal período de relações de poder desequilibradas não pode ser considerado negligenciável) e propor, muito concretamente, outros. Essa pesquisa dialoga com a história do teatro. Ela serve a outros ("Um autor que não ensina nada a escritores não ensina nada a ninguém" (BENJAMIN, 2003, p. 138) na medida em que é controversa e que o saber que dela emerge pode ser potencialmente cumulativo, útil. 
Mas deve-se desconfiar da generalidade. Se tentarmos ler essas propostas como interiorizadas a uma constelação, heterogênea e contraditória, de anticapitalismo militante, a questão torna-se complexa. A "igualdade" pode ser considerada como um dos principais significantes da política da emancipação, e as obras contemporâneas se esforçam para organizar a sessão teatral com base em sua eficácia. As dificuldades, portanto, abundam: o que significa estabelecer uma relação igualitária entre a obra, "o palco" e seu espectador? O menor dos desafios não é de impor no centro de uma estrutura social ontologicamente desigual, competitiva, assimétrica, a existência dessa possibilidade. Propostas tão distintas, entre outras, como as apresentadas por Benoît Lambert (We are la France, We are l'Europe, Bienvenue dans l'espèce humaine [Somos França, Somos Europa, Bem-vindos à espécie humana]) e as de Marie-José Malis(Le Prince de Hombourg [O príncipe de Hombourg], Hypérion) sugerem a mesma atenção à possibilidade igualitária, o desejo semelhante de incluir a representação em seu exercício, assim como revelam as distinções políticas que, a longo prazo, se opõem às abordagens. Se a relação igualitária é um pressuposto ou um pré-requisito, isso altera fundamentalmente o "pacto dramático"3 e a organização sensível da sessão teatral.

Colocar, nesses termos, a experiência da qual o teatro acaba sendo o lugar - o teste da igualdade - nos permite observar a experimentação à luz, não mais apenas do teatro (o que a política produz sobre ele), mas da questão política - emancipatória: o que o teatro traz à política, ou seja, à sua atividade e ao seu pensamento? Neste exemplo, um ponto é particularmente notável: o que se transforma na apreensão do tempo. O teatro propõe, de certa forma, "viver antecipadamente um futuro de progresso infinito" (RANCIÈRE, 2005, p. 23). A questão é importante: ela não sugere a perenebilidade dessa relação. E não se furta ao verdadeiro estado das contradições sociais. Ela não resolve nada. Mas enfrenta a homogeneidade do presente - - considerando-se certo, que por definição, o teatro, compõe sempre um tempo fictício, por mais vastas que sejam as possibilidades e os jogos jogados sobre esta ficção, apenas a ênfase aqui é colocada no valor político dessa "experiência do tempo". De certa forma, à dor e ao pessimismo - derrotismo - produzidos

3 Ver O. Neveux, « "Une politique de pur soleil”. Sur Hypérion de Hölderlin, mis en scène par Marie-José Malis » (BIDENT ; TRIAU, 2015; NEVEUX, 2013a, 2013b). 
pela análise da situação concreta, ela contrasta "o poder da esperança e da ação que deriva da percepção da ausência de qualquer necessidade histórica, do reconhecimento do contingenciamento de toda dominação e dos potenciais ainda desconhecidos da inteligência compartilhada por todos" (GAME; LASOWSKI, 2006; RANCIÈRE, 2009b). Esse choque de tempos não significa, contudo, associar-se a qualquer "ilusão estética", assim como existe uma "ilusão social", que faria da arte um espaço autossuficiente à emancipação e puro dos compromissos e ambivalências que impõe a prática política (seria esta uma das responsabilidades atuais da obra política: inventar os sinais de sua heterogeneidade junto ao ato político?) A coexistência de temporalidades aparentemente irreconciliáveis, o tempo do presente das relações sociais, o tempo dos passados frustrados e o tempo do futuro convocado no presente (e, como tal, todos perturbados em suas supostas "naturezas") perturbam a sucessão mecanicista (progressiva, teleológica ou causalista) das temporalidades - e assim se distingue, participa ativamente dentro dos pensamentos de emancipação. Passado, presente, futuro tornam-se noções ambíguas, o tempo, "fator de interdição" (RANCIÈRE, 2012, p. 108), perde sua arrogância. "Mais tarde" colide com projetos sempre adiados, o presente, complexo e denso, mostra-se disponível para o que lhe é, alhures, proibido. O teatro pode então tornar-se, à sua maneira, a antecipação de um mundo ${ }^{4}$ que nenhuma necessidade, além da política, atesta. Ou melhor: a antecipação em um mundo, pois este permanece singular e fragmentado. Este é a experiência proposta, provisória, saborosa ou confusa, de relações transformadas, a experimentação de suas formas tanto quanto o teste concreto das escolhas, das concepções polêmicas e dos arranjos que elas implicam.

Esse primeiro nível - o que a obra verifica e inventa da política - é enriquecido por uma segunda dimensão: aquela que a arte mantém com a totalidade social. No contexto do teatro político, esboçado aqui, isso se devido ao caráter contributivo ou ao lugar que a obra ocupa no "movimento real que abole a ordem vigente", ou seja, seu valor negativo que suspende, de certa modo, a coagulação, sem resto ou resíduos, da vida desigual e administrada.

4 Ver sobre a antecipação de outra "configuração da comunidade" a leitura que J. Rancière propõe sobre as Cartas de uma Educação Estética da Humanidade de Schiller, particularmente em seu livro (RANCIÈRE, 2004, p. 48). 
Por definição, essa "negatividade" nunca é dada eternamente, ela supõe seu ajuste para que a obra intervenha e desfaça a (falsa) harmonia. Ela produz, então, simultaneamente, a experiência - estratégica - daquilo que resiste e a experimentação - tática - do amargor que as circunstâncias exigem. O teatro - para além do teatro político só, mas imperiosamente para ele - pode ser a experiência renovada dessa intervenção como uma investigação sobre a possibilidade de uma "saída", necessariamente fugaz e parcial, à dominação.

Considerar a pesquisa em que o teatro político é tema e objeto nos leva a considerá-lo no movimento que cria com seu exterior, que se pode dizer que é de "inspiração". O teatro político é, de fato, inspirado pela sociedade e pela história - sua função, seus afetos, suas formas - dialeticamente ligados a eles. Mas, por sua vez, pode inspirá- - los - desde que seja assumido, trabaIhado. As apostas do teatro político, então, constituem-se menos da produção de impactos sobre o espectador - ao que muitas vezes é reduzido, em relação ao quê é tantas vezes julgado - do que na experiência política que promove, ou seja, na prática e concepção desta última, por vezes embaraçosa, que ele torna então possível e pensável.

\section{Referências Bibliográficas}

BATAILLE, G. Le surréalisme et Dieu. Critique, Paris, n. 28, p. 843-844, 1948.

BATAILLE, G. Oeuvres complètes, tome XI: Articles I, 1944-1949. Paris: Editions Gallimard, 1988.

BENJAMIN, W. L'auteur comme producteur: Allocution à l'institut pour l'étude du fascisme à paris, le 27 avril 1934. In: BENJAMIN, W. (ed.). Essais sur Brecht. Tradução Philippe Ivernel. Paris: La Fabrique, 2003. p. 122-144.

BENSAÏD, D. Les Trotskysmes. Paris: PUF, 2002.

BENSAIID, D. Passion Karl Marx: Les hiéroglyphes de la modernité. Paris: Textuel, 2001.

BIDENT, C.; TRIAU, C. Théâtre/Public, Lyon, n. 216, p. 14-23, 2005.

BRECHT, B. Ecrits sur le théâtre. Paris: Editions Gallimard, 2000.

DORT, B. Théâtre public: Essais de critique. Paris: Editons du Seuil, 1967.

GAME, J.; LASOWSKI, A. W. (dir.). Politique de l'esthétique. Paris: Archives Contemporaines Editions, 2006.

GARO, V. I. L'Or des images: art, monnaie, capital. Paris: La Ville brûle, 2013.

IVERNEL, V. P. Introduction générale. COLLECTIF. Le théâtre d'agit-prop de 1917

à 1932: Tome I: L'URSS: recherches. Lausanne: La Cité, 1977. 
LE JARDIN S'EMBRASE. Les Mouvements sont faits pour mourir. Paris: Tahin Party, 2007.

NEVEUX, O. Bienvenue dans l'espèce humaine de Benoît Lambert. Théâtre/Public, Lyon, n. 207, p. 43-54, 2013a.

NEVEUX, O. Contributions politiques: $15 \%$ de Bruno Meyssat. Théâtre/Public, Lyon, n. 207, 2013b.

NEVEUX, O. Une conception tactique et stratégique du spectateur? Quatre propositions sur la politique et le théâtre. Théâtre/Public, Lyon, n. 208, p. 25-29, 2013c.

ORGANISATION DES JEUNES TRAVAILLEURS RÉVOLUTIONNAIRES. Le militantisme, stade suprême de l'aliénation: Le révolutionnaire est au militant ce que le loup est à l'agneau. Paris: Organisation des Jeunes Travailleurs Révolutionnaires, 1972.

THEVENIN, N. E. L'inconnu devant soi: Karl Popper et l'angoisse du théoricien moderne. Paris: Editions Kimé, 2009.

RANCIĖRE, J. La Mésentente: Politique et philosophie. Paris: Galilée, 1995.

RANCIĖRE, J. Malaise dans l'esthétique. Paris: Galilée, 2004.

RANCIÈRE, J. La Méthode de l'égalité: entretiens avec L. Jeanpierre et D. Zabunyan.

Paris: Bayard, 2012.

RANCIÈRE, J. Chroniques des temps consensuels. Paris: Seuil, 2005.

RANCIĖRE, J. Déconstruire la logique inégalitaire. In: RANCIÈRE, J. Et tant pis pour les gens fatigués: entretiens. Paris: Editions Amsterdam, 2009a.

RANCIĖRE, J. Politique de l'indétermination esthétique. In: GAME, J.; LASOWSKI, A. W. (dir.). Politique de l'esthétique. Paris: Archives Contemporaines Editions, 2009b. p. 157-175.

VITEZ, A. Ecrits sur le théâtre, 5: Le Monde. Paris: P.O.L, 1998.

Recebido em 26/06/2020 Aprovado em 03/07/2020

Publicado em 12/08/2020 